Mens

revue d'histoire intellectuelle de l'Amérique française

\title{
Ronald Rudin. Founding Fathers: The Celebration of Champlain and Laval in the Streets of Quebec, 1878-1908. Toronto, University of Toronto Press, 2003. 290 p.
}

\section{E. A. Heaman}

Volume 6, numéro 1, automne 2005

URI : https://id.erudit.org/iderudit/1024262ar

DOI : https://doi.org/10.7202/1024262ar

Aller au sommaire du numéro

Éditeur(s)

Centre de recherche en civilisation canadienne-française

ISSN

1492-8647 (imprimé)

1927-9299 (numérique)

Découvrir la revue

Citer ce compte rendu

Heaman, E. A. (2005). Compte rendu de [Ronald Rudin. Founding Fathers: The Celebration of Champlain and Laval in the Streets of Quebec, 1878-1908. Toronto, University of Toronto Press, 2003. 290 p.] Mens, 6(1), 124-126.

https://doi.org/10.7202/1024262ar d'utilisation que vous pouvez consulter en ligne. 


\section{Ronald Rudin. Founding Fathers: The Celebration of Champlain and Laval in the Streets of Quebec, 1878-1908. Toronto, University of Toronto Press, 2003. $290 \mathrm{p}$.}

L'identité du Québec était celle qui n'osait dire son nom. Tout le monde semblait reconnaître que la province avait une histoire remarquable et de grandes réalisations à célébrer. Mais cette réussite était-elle due au leadership combatif de l'Église catholique ou aux bienveillantes et tolérantes institutions britanniques ? Les commémorations organisées par le clergé en l'honneur de $\mathrm{M}^{\mathrm{gt}}$ Laval supposaient la première option alors que celles organisées par le gouverneur général britannique, le comte Grey, en l'honneur de Champlain prenaient pour acquis la seconde. Néanmoins, aucun parti ne pouvait afficher ouvertement ses présupposés idéologiques. Le gouverneur Grey et ses collaborateurs décidèrent ainsi de minimiser l'impérialisme et de plutôt mettre en valeur des reconstitutions historiques caractérisées par la collaboration des Français et des Anglais, de l'État et de l'Église au sein du Canada. Le tableau historique marquant le tricentenaire de la fondation de Québec par Champlain, un Français, se déroula sur les Plaines d'Abraham, encore que les organisateurs prirent soin de commémorer également la bataille de Sainte-Foy. Comme Rudin le fait remarquer, "As long as no one talked too explicitly about the early-twentieth-century British Empire, the grumbling about the marginal role occupied by Champlain could be kept to a minimum, and everyone could go home feeling reasonably happy. » (p. 213) Pendant ce temps, les organisateurs catholiques des cérémonies en l'honneur de $\mathrm{M}^{\mathrm{gr}}$ Laval espéraient voir leur premier évêque être canonisé. Ils devaient donc respecter, ou du moins ne pas défier trop ouvertement, l'interdiction faite par le Vatican de vénérer 
publiquement les candidats à la sainteté. Ainsi, s'ils organisèrent des cérémonies religieuses et des processions publiques, ils prirent bien soin de ne pas organiser des cérémonies religieuses publiques et firent en sorte que les processions respectassent les normes des fêtes publiques traditionnelles. En fait, grâce à leur longue expérience dans l'organisation de rituels pour les fidèles, les prêtres réussirent mieux leurs commémorations que les organisateurs des commémorations de Champlain dont les tableaux et les défilés historiques attirèrent un auditoire peu important et qui durent abandonner leur plan d'ériger une «Déesse de la Paix » colossale sur les Plaines.

La politique est à l'avant-scène et au cœur du récit de Rudin. Les impérialistes et les ultramontains y apparaissent comme des rivaux jaloux. Ils font de brèves apparitions dans les célébrations orchestrées par leurs vis-à-vis, tout en s'efforçant de les contenir et de leur nuire. Chaque camp en appelle prudemment à tous les habitants du Québec, tentant de combler le fossé entre l'Église et le peuple ou entre l'empire, la métropole et la colonie, alors que certains hommes d'État comme Laurier essaient de trouver un semblant de terrain d'entente. Les tableaux historiques et les défilés aident à effacer les frontières entre les interprètes et les observateurs, entre les créateurs de la propagande et leur cible. Rudin semble soutenir qu'ils ont réussi. Il voit le tournant du siècle comme une " narrow window of opportunity " pour ce genre de commémorations, une époque où le peuple croyait réellement que de somptueuses représentations publiques pouvaient "profoundly transform society" (p. 234). Cette croyance trouve un écho dans la réponse que Jules-Paul Tardivel donne aux cérémonies en l'honneur de Champlain. Dans une déclaration emplie de ferveur, il exhorte les Canadiens français à ignorer et à défier les appels au cosmopolitisme : «Restons 
nous-mêmes » (p. 100). Néanmoins, Tardivel était lui-même né aux États-Unis de parents européens. Dans son ouvrage très détaillé, Rudin évite d'aborder la difficile question de savoir si les habitants de la province voyaient leur identité comme étant statique ou en mouvement. Toutefois, il fournit une description fascinante de la manière dont quelques-uns des bâtisseurs d'identité les plus assidus ont agi dans le Québec du tournant du siècle.

\section{E. A. Heaman Département d'bistoire \\ Université McGill}

Traduction : Michel Ducharme

NDLR : La traduction francaise de cet ouvrage est parue aux Presses de l'Université Laval en 2005 sous le titre L'histoire dans les rues de Québec. La célébration de Champlain et de $\mathrm{M}^{\mathrm{gr}}$ de Laval 1878-1908.

\section{Gérard Bouchard. Raison et contradiction. Le mythe au secours de la pensée. Éditions Nota bene / CEFAN, Québec, 2003. 131 p.}

Ce court ouvrage, qui est la reproduction d'une conférence donnée à l'hiver 2003 à l'Université Laval, paraittra familier à ceux ayant lu l'étude que Gérard Bouchard a consacrée à Lionel Groulx. En effet, l'historien saguenayen reprend ici, tout en les approfondissant, certains des éléments théoriques qui lui ont permis d'examiner la pensée du chanoine. 